\title{
Influence of vitamin D binding protein polymorphism, demographics and lifestyle factors on vitamin D status of healthy Malaysian pregnant women
}

Siew-Siew Lee ${ }^{1}$, King-Hwa Ling ${ }^{2,3}$, Maiza Tusimin ${ }^{4}$, Raman Subramaniam ${ }^{5}$, Kartini Farah Rahim ${ }^{6}$ and Su-Peng Loh ${ }^{1,7^{*}}$ (D)

\begin{abstract}
Background: Vitamin D deficiency (VDD) has been related to vitamin D binding protein (GC) gene polymorphism, demographics and lifestyle factors in different populations. However, previous studies only focused on demographic and lifestyle factors or genetic factors alone. Therefore, this cross-sectional study aimed to assess the association between GC gene polymorphism, demographics and lifestyle factors with VDD among Malaysian pregnant women.

Method: Information on demographic characteristics, dietary vitamin D intake from supplement and food, time spent outdoors, skin type and clothing were collected using a questionnaire. Plasma total 25-hydroxyvitamin D (25OHD) levels were measured using an Ultra-High-Performance Liquid Chromatography (UHPLC). Maternal GC single nucleotide polymorphisms (SNPs) (rs4588 and rs7041) were determined using restriction fragment length polymorphism (RFLP) technique.

Results: Results showed that $50.2 \%$ of pregnant women were vitamin D deficient $(250 \mathrm{HD}<30 \mathrm{nmol} / \mathrm{L})$. VDD $(25 \mathrm{OHD}<30 \mathrm{nmol} / \mathrm{L})$ was significantly associated with age, veiled clothing, maternal vitamin $D$ intakes from both food and supplements, and GC rs7041 (and GC diplotypes). In contrast to previous studies that reported for nonpregnant population, a significant positive association was found between CC genotype for SNP GC rs7041, GC 1s$1 \mathrm{~s}$ and GC If-2 with risk of VDD $(25 \mathrm{OHD}<30 \mathrm{nmol} / \mathrm{L})$.

Conclusions: The high prevalence of maternal VDD found in this study suggests the need for urgent development and implementation of vitamin D supplementation or fortification strategies to reduce VDD among pregnant women. The discrepancy in the association between GC rs7041 gene polymorphism and VDD reflects the variation in the factors associated with VDD in pregnancy compared to non-pregnant state.
\end{abstract}

Keywords: Vitamin D deficiency, Pregnant women, Single nucleotide polymorphism, Vitamin D binding protein

\footnotetext{
* Correspondence: sploh@upm.edu.my

${ }^{1}$ Department of Nutrition, Faculty of Medicine and Health Sciences, Universiti

Putra Malaysia, 43400 UPM Serdang, Selangor, Malaysia

${ }^{7}$ Research Centre of Excellence for Nutrition and Non-Communicable

Diseases, Faculty of Medicine and Health Sciences, Universiti Putra Malaysia,

43300 UPM Serdang, Selangor, Malaysia

Full list of author information is available at the end of the article
}

(C) The Author(s). 2020 Open Access This article is licensed under a Creative Commons Attribution 4.0 International License, which permits use, sharing, adaptation, distribution and reproduction in any medium or format, as long as you give appropriate credit to the original author(s) and the source, provide a link to the Creative Commons licence, and indicate if changes were made. The images or other third party material in this article are included in the article's Creative Commons licence, unless indicated otherwise in a credit line to the material. If material is not included in the article's Creative Commons licence and your intended use is not permitted by statutory regulation or exceeds the permitted use, you will need to obtain permission directly from the copyright holder. To view a copy of this licence, visit http://creativecommons.org/licenses/by/4.0/. The Creative Commons Public Domain Dedication waiver (http://creativecommons.org/publicdomain/zero/1.0/) applies to the data made available in this article, unless otherwise stated in a credit line to the data. 


\section{Background}

Vitamin D is well known for its role in regulating bone metabolism by stimulating intestinal calcium and phosphorus absorption [1]. Recent findings showed that vitamin $\mathrm{D}$ also plays a vital role in cellular proliferation and regulation, trophoblast invasion, and immunomodulation at the maternal-fetal interface [2, 3]. Maternal vitamin $\mathrm{D}$ deficiency (VDD) has been suggested as a potential mechanism in mediating the pathogenesis of adverse pregnancy and neonatal outcomes, including preeclampsia [4, 5], gestational diabetes [6], small for gestational age $[7,8]$ and preterm birth [9].

Globally, it was estimated that $50-80 \%$ of pregnant women are deficient of vitamin D (25-hydroxyvitamin D $(25 \mathrm{OHD})<50 \mathrm{nmol} / \mathrm{L})$ [10]. Findings from previous epidemiological studies have demonstrated that VDD was high in countries that are located at a high latitude [10]. Recent studies also reported a high prevalence of VDD in countries with abundant sunshine such as Spain [11], India [12], Thailand [13, 14], and Malaysia [15]. In countries located at high latitudes such as the United Kingdom [16] and the Netherlands [17], a routine vitamin D supplementation is recommended for a specific group at risk, particularly pregnant women. Despite the high prevalence of VDD among pregnant women in the region with abundant sunshine like Malaysia, routine vitamin D supplementation has not been established due to insufficient data to inform vitamin D supplementation for pregnant women.

Previously, VDD has been related to environmental and lifestyle factors including latitude, season, sun exposure, skin type, clothing, dietary vitamin D intake, Body Mass Index (BMI) and ethnicity [18]. Several genome-wide association studies (GWAS) and candidate gene studies have shown that single nucleotide polymorphisms (SNPs) were associated with vitamin D status [19-22]. These SNPs located in or close to the genes encode the key enzymes or proteins for the metabolism, transportation and action of the mechanism of vitamin $\mathrm{D}$, such as cytochrome P450-2R1 (CYP2R1), cytochrome P450-27B1 (CYP27B1). Nonetheless, the studies related the association of the SNPs and vitamin D status were largely conducted for the non-pregnant women [19-22]. Also, previous studies focused on the factors associated with VDD during pregnancy were restricted to the study of only environmental $[15,23,24]$ or genetic factors only [25-28].

In a review [29] that included a total of 120 genetic associations studies, it was reported that SNPs in GC, particularly rs7041 and rs4588 are the most reported SNPs associated with the level of 25OHD. Furthermore, SNP rs7041 and rs4588 are missense SNPs (functional SNPs) where the variation in the nucleotide resulted in the change in amino acid and vitamin $\mathrm{D}$ binding protein glycosylation pattern. For rs7041, A to C allele transversion causes the change of amino acid aspartic acid (CTA) to glutamic acid (CTC), whereas, for rs 4588 , G to $\mathrm{T}$ allele transversion causes the change of amino acid Threonine (TGC) to Lysine (TTC) [30]. The combination of the two SNPs (rs4588 and rs7041) has resulted in three different $G C$ haplotypes/isoforms: GC1f (A allele rs7041 and $\mathrm{G}$ allele rs4588), $G C 1$ s (C allele rs7041 and $\mathrm{G}$ allele rs4588) and $G C 2$ (A allele rs7041 and $\mathrm{T}$ allele rs4588). These three $G C$ haplotype/isoforms gave rise to $6 G C$ diplotypes: $1 \mathrm{f} / 1 \mathrm{f}, 1 \mathrm{~s} / 1 \mathrm{~s}, 2 / 2,1 \mathrm{f} / 1 \mathrm{~s}, 1 \mathrm{f} / 2,1 \mathrm{~s} / 2$ with different binding affinities and post-translational glycosylation [31, 32].

Besides being the major transport protein for all the vitamin D metabolites, vitamin D binding protein is important to keep 25OHD in the circulation pool [33]. Different $G C$ isoforms have been linked to different vitamin $\mathrm{D}$ binding protein concentrations in postmenopausal women [33], infants and toddlers [34]. The variation in the level and functionality of vitamin $\mathrm{D}$ binding protein has been postulated to directly or indirectly affect the 25OHD level in the blood circulation. During pregnancy, the concentration of vitamin $\mathrm{D}$ binding protein is elevated by two to three folds compared to the nonpregnant (normal) state [35]. Thus, the effect of GC SNPs on vitamin D status among pregnant women may be different from that reported in the non-pregnant population. Therefore, this study aimed to (1) assess the prevalence of VDD, and (2) determine the associations between demographics, lifestyle and $G C$ gene polymorphism (rs7041, rs4588 and the GC diplotypes) with VDD among healthy Malaysian pregnant women.

\section{Methods}

\section{Study design and setting}

This cross-sectional study was conducted from October 2015 through February 2017 at the Department of Gynaecology and Obstetrics Hospital Serdang, Selangor, Malaysia. Hospital Serdang is a public hospital located in Sepang district of Selangor, which caters for a population of about 2 million residents from three districts: Petaling, Sepang and Hulu Langat. This study adhered to the STROBE guidelines for observational studies.

\section{Participants}

Pregnant women were conveniently recruited while they get admitted to the labour suite's Patient Assessment Centre of Hospital Serdang for delivery. Inclusion criteria were Malaysian, aged 19 to 40 years, singleton pregnancy and week of pregnancy $\geq 37$ weeks. Pregnant women who were diagnosed with pre-existing systemic disease, pregnancy complications, and had a history of bone and renal disorders were excluded from the study. 
Using an estimated prevalence of vitamin D deficiency $(<25 \mathrm{nmol} / \mathrm{L})$ in pregnant Malaysian women of $37 \%$ [23] and precision of $7 \%$ with a $95 \%$ confidence interval, the sample size was calculated to be 192 using the formula [36]: $n=Z^{2} P(1-P) / d^{2}$. The addition of $20 \%$ for nonresponse gave a minimum sample size of 245 pregnant women.

\section{Data collection and blood sampling}

Information on maternal ethnicity, education level, employment status and household income were selfreported using an interviewer-administered questionnaire. Maternal age, gestational age, last menstrual period (LMP), first booking (date, weeks, and ultrasound scan), gravidity, pre-pregnancy weight and heights were obtained from hospital electronic medical record and antenatal record. Gestational age was determined by LMP and confirmed by the first dating scan. Body Mass Index (BMI) was calculated as body weight divided by squared of body height $\left(\mathrm{kg} / \mathrm{m}^{2}\right)$. Venous blood was collected from pregnant women on the day of labour. All collected blood samples were processed within the collection day. After centrifugation, plasma was aliquoted, and buffy coat was collected for subsequent deoxyribonucleic acid (DNA) extraction.

The duration of exposure to sunlight per week was estimated using a questionnaire adapted from a previous study [37]. Pregnant women were asked about their outdoor activities from 7 am to $7 \mathrm{pm}$ over the past 1 month. Information on the type of activity, duration (in minutes), usual outdoor attire, frequency (per week), use of glove, umbrella, and sunscreen were recorded. Based on the attire worn, the percent of body surface area (BSA) exposed to sunlight was estimated using the "Rule of Nine".

In general, the climate in Selangor, Malaysia is warm to hot with an average daily sunshine of $6 \mathrm{~h}$ throughout the year. The region is typically affected by north-east monsoon (November-February; rainy season) and south-west monsoon (May to September, relatively dry season). Time spent outdoors and average available sunlight may vary between rainy and dry season [38]. As 25OHD has 3 weeks of half-life in blood circulation, exposure to sun for about 4 weeks before drawing the blood sample may better correlate with the circulating 25OHD. Therefore, in the present study, month of blood sampling was dichotomised into December to March and April to November.

To estimate the skin colour of the study participants, the Fitzpatrick scale [39] was used. Based on the women skin colour and skin tanning evaluation, study participants were classified into six different skin phototypes. In this study, as the sample size of each skin type subset was small, particularly skin type I, II, V and VI, skin colour types were dichotomised into light skin colour (Fitzpatrick scale I to III) and dark skin colour (Fitzpatrick scale IV and V) [40].

Daily vitamin D intake from dietary and supplemental sources was assessed using a vitamin D-specific semiquantitative Food Frequency Questionnaire (FFQ) which was adapted from a previous study [41]. Pregnant women were asked to recall the brand (for commercial food), frequency and serving size of the listed food they had consumed over the past 1 month. At the same time, the pregnant women also provided the information regarding their supplemental intakes over the past 1 month: supplements (e.g. brand name, type of supplements, and specific nutrient), frequency and dosage of intake. To minimise the bias on depth and nature of probing, sun exposure and FFQ was administered by only one trained interviewer. The complete questionnaires used in this study is shown in Supplementary File 1.

\section{Measurement of plasma 250HD}

Plasma concentrations of $25 \mathrm{OHD}_{3}$ and $25 \mathrm{OHD}_{2}$ were determined using an ultra-high-performance liquid chromatography (UHPLC) and summed to calculate total plasma 25OHD. The inter-assay coefficient of variation at $50 \mathrm{nmol} / \mathrm{L}$ were 6 and $7 \%$ for $25 \mathrm{OHD}_{3}$ and $25 \mathrm{OHD}_{2}$, respectively. Multiple cut-offs $(<25,<30$ and $<$ $50 \mathrm{nmol} / \mathrm{L}$ ) were used to describe the prevalence of maternal VDD. The cut-off of National Academy of Medicine (formerly known as Institute of Medicine [IOM]) $(<30 \mathrm{nmol} / \mathrm{L})$ which is associated with an increased risk of VDD [42] was used in the analysis of factors associated with maternal VDD.

\section{Genotyping}

DNA was extracted from the buffy coat using the QIAamp DNA blood kit (QIAGEN, Germany) following to the manufacturer's protocol. DNA yields and quality were determined using the NanoVue Plus UV spectrophotometer (GE Healthcare, USA).

Genotyping of GC SNPs rs4588 and rs7041 were carried out by restriction fragment length polymorphism (RFLP) technique. PCR was performed using a thermocycler (Thermo Fisher Scientific, USA). The PCR reaction mixture was prepared in a total volume of $20 \mu \mathrm{L}: 10 \mu \mathrm{L}$ of $2 \mathrm{X}_{\text {GoTaq }^{\circ} \mathrm{G} 2}$ Green Master Mix (Promega, USA), $1 \mu \mathrm{L}$ each of $10 \mathrm{nmol}$ forward primer (5'-AAATAATGAGCAAATGAAAGAAGAC-3') and reverse primer $\left(5^{\prime}\right.$ - CAATAACAGCAAAGAAATGAG TAGA-3'), $3 \mu \mathrm{L}$ of nuclease-free water and $5 \mu \mathrm{L}$ of DNA $(15 \mathrm{ng} / \mu \mathrm{L})$. The PCR conditions for amplification included an initial step of denaturation at $95^{\circ} \mathrm{C}$ for $10 \mathrm{~min}$ followed by 35 cycles of denaturation at $95^{\circ} \mathrm{C}$ for $45 \mathrm{~s}$, annealing at $51{ }^{\circ} \mathrm{C}$ for $45 \mathrm{~s}$ and elongation at $72{ }^{\circ} \mathrm{C}$ for $45 \mathrm{~s}$, and finally a step of final extension step at $72^{\circ} \mathrm{C}$ for 
7 min. The PCR product, a 483-bp fragment was then digested separately using restriction enzyme, HaeIII (for rs7041) and StyI (for rs 4588) (New England Biolabs Inc., USA) in a total reaction volume of $20 \mu \mathrm{L}$. The digested products were then evaluated by electrophoresis on $1.5 \%$ agarose gel stained with ethidium bromide.

\section{Statistical analysis}

Statistical analysis was performed using SPSS version 21.0 (SPSS Inc., Chicago, USA). All the variables have less than $5 \%$ missing data and single imputation technique was applied [43]. All the continuous variables were assessed for normality using skewness and kurtosis test. Mean and standard deviation (SD) were presented for normally distributed variables, whereas median and interquartile range (IQR) were presented for skewed variables. All the categorical variables were reported as numbers and proportions. Differences in the proportion of GC SNPs and diplotypes between ethnicity, and the Hardy-Weinberg Equilibrium (HWE) for each SNPs were examined using Chi-square test.

Individual associations between factors and VDD $(25 \mathrm{OHD}<30 \mathrm{nmol} / \mathrm{L})$ were determined using univariate binary logistic regression. To further evaluate the joint associations of demographic, lifestyle and genetic factors with the risk of maternal VDD, multivariate logistic regression was performed. Variables that had $p$-value $<0.25$ in univariate analyses and biologically important were included in multivariate analyses. Cramer's $\mathrm{V}$ and Pearson's correlation coefficient were used to test the associations between variable. Variables with $r^{2}>0.6$ were considered highly correlated and excluded from the multivariate regression. Two separate multivariate models were constructed to determine the factors associated with VDD. Model 1 included selected demographic characteristics, lifestyle factors and the two GC SNPs (rs7041 and rs4588); Model 2 consisted of the demographics, lifestyle factors and $G C$ diplotypes. All the statistical significance was specified at $p$-value $<0.05$.

\section{Results}

\section{Characteristics of participants}

A total of 248 pregnant women provided informed consent to participate in the study. There were 217 of women had blood specimen, complete questionnaire and medical records, thus included in the analysis. Table 1 summarises the characteristics of study participants. The majority of study participants (86.2\%) were Malays with the mean age of $29 \pm 4$ years. The percentage of participants with an education level up to tertiary education was slightly higher (56.7\%) compared with secondary or lower $(43.3 \%)$. Nearly $50 \%$ of the participants had a monthly household income in the range of
Table 1 Characteristics of study participants

\begin{tabular}{|c|c|}
\hline Characteristics & $N=217$ \\
\hline \multicolumn{2}{|l|}{ Ethnicity, n (\%) } \\
\hline Malay & $187(86.2)$ \\
\hline Chinese & $20(9.2)$ \\
\hline Indians and others ${ }^{c}$ & $10(4.6)$ \\
\hline \multicolumn{2}{|l|}{ Parity, n (\%) } \\
\hline Nulliparous & $58(26.7)$ \\
\hline Multiparous & $159(73.3)$ \\
\hline \multicolumn{2}{|l|}{ Maternal highest education level, n (\%) } \\
\hline Secondary and lower & $94(43.3)$ \\
\hline Tertiary and higher & $123(56.7)$ \\
\hline \multicolumn{2}{|l|}{ Household Income (per month), n (\%) } \\
\hline$\leq \mathrm{RM} 3000$ & $64(30.0)$ \\
\hline RM3001-RM5000 & $94(44.1)$ \\
\hline$\geq$ RM5001 & $55(25.9)$ \\
\hline \multicolumn{2}{|l|}{ Month of sampling, n (\%) } \\
\hline December-March & $76(35.0)$ \\
\hline April-November & $141(65.0)$ \\
\hline \multicolumn{2}{|l|}{ Fitzpatrick skin type, n (\%) } \\
\hline Light (Type I, II, III) & $97(44.7)$ \\
\hline Dark (Type IV, V \&VI) & $120(55.3)$ \\
\hline \multicolumn{2}{|l|}{ Veiled, n (\%) } \\
\hline Yes & $179(82.5)$ \\
\hline No & $38(17.5)$ \\
\hline \multicolumn{2}{|c|}{ Use of supplement containing vitamin D, n (\%) } \\
\hline Yes & $87(40.1)$ \\
\hline No & $130(59.9)$ \\
\hline Maternal age (in years) ${ }^{a}$ & $29 \pm 4$ \\
\hline Week of pregnancy ${ }^{a}$ & $39.1 \pm 1.1$ \\
\hline Pre-pregnancy BMI $\left(\mathrm{kg} / \mathrm{m}^{2}\right)^{a}$ & $23.7 \pm 5.1$ \\
\hline Time spent outdoors per week (hours) & $1.9(0.7-4.1)$ \\
\hline$\%$ BSA exposed to sunlight ${ }^{b}$ & $6.5(6.5-6.5)$ \\
\hline VD intake from food ( $\mu \mathrm{g} /$ day $)^{a}$ & $8.3 \pm 5.0$ \\
\hline VD intake from supplement $(\mu \mathrm{g} / \text { day })^{a}$ & $3.8 \pm 5.6$ \\
\hline Plasma Total $250 \mathrm{HD}(\mathrm{nmol} / \mathrm{L})^{b}$ & $29.8(18.8-43.5)$ \\
\hline
\end{tabular}

Note: Categorical variables are presented as $\mathrm{n}$ (percentages); ${ }^{\text {a variable is }}$ presented as mean \pm standard deviation; ${ }^{b}$ variables are presented as median (first quartile, third quartile)

cOthers included Kadazan $(n=1)$, Bajau $(n=1)$, Suluk $(n=1)$ and mixed ethnic $(n=1)$

RM3001 to RM5000 (approximately USD 750-1600). One-hundred and forty-one participants (65.0\%) were enrolled between April and November (2015-2017), while $76(35.0 \%)$ were enrolled in the study between December and March (2015-2017).

The median time spent outdoors per week was 1.9 (range: 0.7-4.1) hour. As the majority of the study 
participants were Malay, about $82.5 \%$ of participants were veiled. Median \% BSA exposed to sunlight was $6.5 \%$, which was consistent with the usage of veiled clothing (covered on the head, with long sleeve and long pants) and sandals. Not more than half of the respondents (40.1\%) consume vitamin D containing supplements.

Table 2 shows the distribution of the GC SNPs and diplotypes in the study participants. The genotype distribution for the two SNPs were in Hardy-Weinberg equilibrium $\left(x^{2}<0.3841, \quad p>0.05\right)$. Minor allele frequencies for $G C$ rs4588 ( $\mathrm{T}$ allele) and $G C$ rs7041 (C allele) were 21 and 37\%, respectively. The results showed heterogeneity of the allele frequencies for the two GC SNPs between ethnicity. The frequency of the rs4588 $\mathrm{T}$ allele was significantly higher in Chinese (35.0\%) than Malay, Indians and other ethnicities $(19.0 \%)\left(x^{2}=4.904, p<0.015\right)$. The $G C$ rs7041 C allele showed the trend of lower frequency among Chinese (23.0\%) than non-Chinese $(38.0 \%)$ participants, although the difference was not statistically significant $(p=0.051)$. For $G C$ diplotypes, $1 \mathrm{f}-1 \mathrm{~s}$ was the most frequent diplotypes in pregnant women but diplotypes
2-2 was found in the lowest frequency $(2.8 \%)$ in the study population.

\section{Prevalence of VDD}

The median (IQR) total 25OHD concentration was $29.8 \mathrm{nmol} / \mathrm{L}\left(\mathrm{Q}_{1}-\mathrm{Q}_{3}=18.8-43.5 \mathrm{nmol} / \mathrm{L}\right)$, with prevalence of vitamin $\mathrm{D}$ status among pregnant women as follows: $<25 \mathrm{nmol} / \mathrm{L} \quad(41.9 \%), \quad<30 \mathrm{nmol} / \mathrm{L} \quad(50.2 \%)$ and $<50 \mathrm{nmol} / \mathrm{L}(82.2 \%)$.

\section{Factors associated with maternal vitamin $D$ deficiency}

Logistic regression analyses showed that the risk factors for VDD $(25 \mathrm{OHD}<30 \mathrm{nmol} / \mathrm{L})$ were higher maternal age and veiled clothing $(p<0.05)$ (Table 3$)$. In contrast, vitamin D intake from food, supplements and the \%BSA were the protective factors $(p<0.05)$.

For genetic factors, the results revealed that the homozygous mutant (CC genotype) of GC rs7041 was associated with an increased risk of VDD when compared to other genotypes (Table 4). Nonetheless, no significant association was found between VDD and SNP GC rs4588. GC diplotype (combinations of rs7041

Table 2 Distribution of GC genotypes and diplotypes by ethnicity

\begin{tabular}{|c|c|c|c|c|c|c|}
\hline & & $\begin{array}{l}\text { Total } \\
(n=217)\end{array}$ & $\begin{array}{l}\text { Malay, Indians \& others } \\
(n=197)\end{array}$ & $\begin{array}{l}\text { Chinese } \\
(n=20)\end{array}$ & $x^{2}$ & $p$-value \\
\hline \multicolumn{7}{|l|}{ GC rs4588 } \\
\hline \multirow[t]{2}{*}{ Allele } & G & $(79.5)$ & $(81.0)$ & $(65.0)$ & 4.909 & 0.015 \\
\hline & T & $(20.5)$ & $(19.0)$ & $(35.0)$ & & \\
\hline \multirow[t]{3}{*}{ Genotype } & GG & $135(62.2)$ & $127(64.5)$ & $8(40.0)$ & & \\
\hline & GT & $76(35.0)$ & $66(33.5)$ & $10(50.0)$ & & \\
\hline & $\pi$ & $6(2.8)$ & $4(2.0)$ & $2(10.0)$ & & \\
\hline \multicolumn{7}{|l|}{ GC rs7041 } \\
\hline \multirow[t]{2}{*}{ Allele } & A & $(63.4)$ & $(62.0)$ & $(77.0)$ & 3.793 & 0.051 \\
\hline & C & $(36.6)$ & $(38.0)$ & $(23.0)$ & & \\
\hline \multirow[t]{3}{*}{ Genotype } & AA & $89(41.0)$ & 78 (39.6) & $11(55.0)$ & & \\
\hline & $A C$ & $97(44.7)$ & $88(44.7)$ & $9(45.0)$ & & \\
\hline & $\mathrm{CC}$ & $31(14.3)$ & $31(15.7)$ & 0 & & \\
\hline \multicolumn{7}{|c|}{ GC diplotypes (rs4588 + rs7041) } \\
\hline \multirow[t]{3}{*}{ Allele } & $1 f$ & $(43.1)$ & $(43.1)$ & $(42.5)$ & 6.934 & 0.031 \\
\hline & $1 \mathrm{~s}$ & $(36.6)$ & $(38.1)$ & $(22.5)$ & & \\
\hline & 2 & $(20.3)$ & (18.8) & $(35.0)$ & & \\
\hline \multirow[t]{6}{*}{ Diplotypes } & $1 f-1 f$ & $44(20.3)$ & $40(20.3)$ & $4(20.0)$ & & \\
\hline & $1 s-1 s$ & $31(14.3)$ & 31 (15.7) & $0(0.0)$ & & \\
\hline & $1 \mathrm{f}-1 \mathrm{~s}$ & 60 (27.6) & $56(28.4)$ & $4(20.0)$ & & \\
\hline & $1 f-2$ & 39 (18.0) & $34(17.3)$ & $5(25.0)$ & & \\
\hline & $1 s-2$ & 37 (17.1) & $32(16.2)$ & $5(25.0)$ & & \\
\hline & $2-2$ & $6(2.8)$ & $4(2.0)$ & $2(10.0)$ & & \\
\hline
\end{tabular}


Table 3 Associations between demographic and lifestyle factors with maternal VDD $(25 \mathrm{OHD}<30 \mathrm{nmol} / \mathrm{L})$ in univariate analysis

\begin{tabular}{|c|c|c|c|}
\hline Covariates & Crude OR & $95 \% \mathrm{Cl}$ & $p$-value \\
\hline \multicolumn{4}{|l|}{ Ethnicity } \\
\hline Malay, Indians and others & 2.56 & $0.94-6.93$ & 0.065 \\
\hline Chinese & 1.00 & Reference & \\
\hline \multicolumn{4}{|l|}{ Parity } \\
\hline Nulliparous & 0.90 & $0.49,1.64$ & 0.728 \\
\hline Multiparous & 1.00 & Reference & \\
\hline \multicolumn{4}{|l|}{ Maternal highest education level } \\
\hline Secondary and lower & 0.98 & $0.58-1.68$ & 0.953 \\
\hline Tertiary and higher & 1.00 & Reference & \\
\hline \multicolumn{4}{|l|}{ Household Income (per month) } \\
\hline$\leq \mathrm{RM} 3000$ & 0.72 & $0.35-1.49$ & 0.373 \\
\hline RM3001-RM5000 & 0.63 & $0.32-1.24$ & 0.181 \\
\hline$\geq$ RM5001 & 1.00 & Reference & \\
\hline \multicolumn{4}{|l|}{ Month of sampling } \\
\hline December-March & 0.66 & $0.37-1.15$ & 0.142 \\
\hline April-November & 1.00 & Reference & \\
\hline \multicolumn{4}{|l|}{ Fitzpatrick skin type } \\
\hline Light (Type I, II, III) & 1.00 & Reference & \\
\hline Dark (Type IV, V \&VI) & 0.63 & $0.36-1.07$ & 0.087 \\
\hline \multicolumn{4}{|l|}{ Veiled } \\
\hline Yes & 2.56 & $1.22-5.40$ & 0.013 \\
\hline No & 1.00 & Reference & \\
\hline Maternal age & 1.08 & $1.01-1.16$ & 0.018 \\
\hline Week of pregnancy & 0.93 & $0.74-1.18$ & 0.572 \\
\hline Pre-pregnancy BMI & 1.02 & $0.97-1.08$ & 0.441 \\
\hline Time spent outdoors per week (h) & 0.68 & $0.35-1.33$ & 0.262 \\
\hline BSA exposed to sunlight & 0.32 & $0.11-0.95$ & 0.039 \\
\hline VD intake from food & 0.93 & $0.88-0.99$ & 0.014 \\
\hline VD intake from Supplements & 0.93 & $0.89-0.98$ & 0.008 \\
\hline
\end{tabular}

$B M I$ Body mass index, VD Vitamin D

and rs4588) $1 \mathrm{~s}-1 \mathrm{~s}$ and $1 \mathrm{f}-2$ were associated with an increased risk of VDD.

Variables that fulfilled the criteria ( $p$-value $<0.25$ in univariate analyses and biologically important) were maternal age, ethnicity, household income (RM3001RM5000), month of sampling, vitamin D intake from food and supplements, Fitzpatrick skin type, percent BSA exposed to sunlight, veiled clothing, SNP rs7041, SNP rs4588 and GC diplotypes.

Strongly correlated variables were excluded to avoid the possibility of multicollinearity problem. As \% BSA exposed to sun and veiled clothing were strongly correlated, a decision was made to include only veiled in the multivariate analysis. Given that ethnicity was overlapped with the variables veiled and skin colour,
Table 4 Associations between GC genotypes and diplotypes with maternal VDD $(25 \mathrm{OHD}<30 \mathrm{nmol} / \mathrm{L})$ in univariate analysis

\begin{tabular}{lllll}
\hline & & Crude OR & $\mathbf{9 5 \%}$ Cl & $\boldsymbol{p}$-value \\
\hline GC rs4588 & GG & 1.00 & Reference & \\
& GT + GT rs7041 & 1.07 & $0.61-1.87$ & 0.814 \\
& AA & 0.65 & $0.37-1.17$ & 0.654 \\
& AC & 1.00 & Reference & \\
GC diplotype & CC & 2.87 & $1.22-6.74$ & 0.016 \\
& If-1f & 1.00 & Reference & - \\
& 1s-1s & 2.76 & $1.06-7.22$ & 0.038 \\
& If-1s & 1.07 & $0.49-2.36$ & 0.854 \\
& 1s-2 & 0.80 & $0.33-1.96$ & 0.626 \\
& If-2 & 2.40 & $0.97-5.70$ & 0.059 \\
& 2-2 & 1.30 & $0.24-7.26$ & 0.753 \\
\hline
\end{tabular}

ethnicity was not included in the multivariate analyses. Based on the univariate analysis, $G C$ rs7041 appeared to have a recessive effect on vitamin D status, while rs 4588 have a dominant effect. Thus, the recessive and dominant models were accounted for SNP rs7041 and rs4588, respectively in the multivariate models. Therefore, the final multivariate models included: age, household income (RM3001-RM5000), the month of sampling, vitamin D intake from food, vitamin $D$ intake from supplements, Fitzpatrick skin type, veiled, $G C$ rs704 and rs4588 genotype (or diplotypes).

In the backward stepwise multivariate analysis (model 1; Table 5), maternal age, vitamin D intake from food, vitamin D intake from supplements, veiled, $G C$ rs7041 SNP and month of blood sampling were significantly associated with VDD (Table 5). The results demonstrated that the risk of VDD increased as the age increased but decreased as the vitamin D intake from food and supplements increased. Pregnant women who were veiled had about 4 times higher risk of VDD compared to pregnant women who did not veil themselves. Likewise, pregnant women who carried homozygous mutant in $G C$ rs7041 SNP had about 3 times higher risk to have VDD compared with other women who carried other genotypes. In a separate multivariate model (model 2), the analysis showed that pregnant women who had diplotypes $1 \mathrm{f}-2$ and $1 \mathrm{~s}-1 \mathrm{~s}$ both had 3-4 times higher risk of VDD compared with pregnant women of other diplotypes. Time spent outdoor, skin type and other factors were not significantly associated with maternal vitamin $\mathrm{D}$ status.

\section{Discussion}

Malaysia is a tropical country where sunlight is available throughout the year. However, the prevalence of VDD among pregnant women is high. An estimate of $82.0 \%$ of maternal plasma $25 \mathrm{OHD}<50 \mathrm{nmol} / \mathrm{L}$ was consistent with previous studies conducted in the local urban area 
Table 5 Multivariate models of demographic, lifestyle, GC genotypes and diplotypes with VDD $(25 \mathrm{OHD}<30 \mathrm{nmol} / \mathrm{L})$

\begin{tabular}{|c|c|c|c|c|c|c|}
\hline \multirow[t]{2}{*}{ Variables } & \multicolumn{3}{|c|}{ Model 1} & \multicolumn{3}{|c|}{ Model 2} \\
\hline & $\mathrm{aOR}$ & $95 \% \mathrm{Cl}$ & $p$-value & $\mathrm{aOR}$ & $95 \% \mathrm{Cl}$ & $p$-value \\
\hline Age & 1.11 & $1.03,1.19$ & 0.006 & 1.11 & $1.03,1.20$ & 0.005 \\
\hline Dietary VD intake & 0.89 & $0.84,0.96$ & 0.001 & 0.89 & $0.83,0.95$ & $<0.001$ \\
\hline Supplemental VD intake & 0.92 & $0.87,0.98$ & 0.004 & 0.91 & $0.86,0.97$ & 0.003 \\
\hline Veiled (Yes) & 4.27 & $1.80,10.11$ & 0.001 & 4.65 & $1.92,11.25$ & 0.001 \\
\hline Month of sampling (Dec-Mar) & 0.50 & $0.26,0.94$ & 0.030 & 0.52 & $0.28,0.99$ & 0.047 \\
\hline GC rs7041 & 2.96 & $1.13,7.76$ & 0.028 & - & - & - \\
\hline GC rs4588 & 0.56 & $0.29,1.08$ & 0.084 & - & - & - \\
\hline GC Diplotype 1f-2 & - & - & - & 3.75 & $1.60,8.77$ & 0.002 \\
\hline GC Diplotye 1s-1s & - & - & - & 3.08 & $1.19,7.99$ & 0.021 \\
\hline
\end{tabular}

(Kuala Lumpur), where 90 and 72\% of VDD (25OHD < $50 \mathrm{nmol} / \mathrm{L}$ ) were found among pregnant women in the first trimester [15] and at delivery [24], respectively. The VDD prevalence reported in the present study $(82.2 \%)$ was higher compared to the previous study $(61.0 \%)$ conducted among pregnant women in a private hospital in Kuala Lumpur [44]. The variation could be attributed to differences in the proportion of ethnicity and socioeconomic background among study participants in present and previous studies. The prevalence of maternal VDD reported in the present study was comparable to that reported in countries located at high latitude, which included Ireland (80.0\%) [45] , Germany (77.0\%) [46] , China (75.0\%) [47] and Japan (73.0\%) [48]. Nevertheless, the VDD prevalence found in the present study was higher compared to that reported in Thailand (20-40\%) $[13,14]$ and India (66.0\%) [12] among pregnant women at delivery and third trimester.

In previous studies, the factors that had been reported to be significantly associated with maternal vitamin D status differ accordingly [49] owing to vitamin D status is country-, ethnic- or subgroup-specific. Besides geographical factor (latitude and UV availability), each country has its own dietary recommendation, vitamin D food fortification strategies and supplementation policy. Likewise, each subgroup or ethnic groups has a different eating habit, clothing, skin colour, physical activity, attitude towards sun exposure and genetic make-up. A combination and interaction of these factors may lead to a risk of VDD in the population. Therefore, there is a need to explore various factors that can increase the risk of VDD for a different country, ethnics, and sub-groups. In this study, the demographic characteristics, lifestyle factors and $G C$ polymorphism that might associated with VDD were comprehensively assessed.

Despite abundance of sunlight throughout the year, no association between time spent outdoors and maternal VDD was noted in this study, likewise the skin type variable. These null results are consistent with that reported in previous local studies, which examined factors associated with VDD in early pregnancy [15]. No association was reported between Fitzpatrick classification, melanin indices, sun protection score and sunlight exposure with maternal VDD [15]. The null results could be due to a high proportion of Malay ethnic group in the study with majority of them (82.5\%) were veiled. In support of this, veiled was identified as a risk of VDD in our study where veiled women were about 4 times at higher risk than unveiled women as UVB rays do not transmit through clothing. This finding is in an agreement with a study conducted in Saudi Arabia [50] where the researchers reported that veiled clothing was significantly associated with increased risk of VDD.

The positive association between vitamin $\mathrm{D}$ intake from food and supplements and maternal VDD is in agreement with most of the previous findings [40, 48, 51-56] except a study [46]. It was found that vitamin D intake from foods and supplements contributed significantly to $25 \mathrm{OHD}$ level in population where exposure to sun is minimum or dermal synthesis of 25OHD is limited. For instances, recent studies from two high latitude countries, Sweden [57] and Switzerland [40, 55]reported that consumption of supplements but not time spent outdoors was associated with decreased risk of VDD. Similarly, in a large Chinese study, Yun and colleagues [47] demonstrated that vitamin D supplement consumption was positively associated with vitamin $\mathrm{D}$ status during winter when the exposure to sunlight is limited but not significantly associated during autumn. In the current study, it was found that exposure to sun did not contribute to the risk of VDD, but dietary vitamin D intake did which is consistent with the findings by Yun and colleagues [47].

Previous studies that investigated the association of $G C$ rs7041 with 25OHD showed that $C$ allele was associated with decreased risk of VDD among pregnant [25-27, 58] and non-pregnant population [19-22]. In contrast to the previous studies, the $\mathrm{C}$ allele was found 
to increase the risk of VDD among pregnant women in the current study. The discrepancy could be due to the factors included in this study were different. For instance, the previous studies examined the factors associated with maternal VDD have been restricted to the only environmental $[15,23,24]$ or genetic variables alone [25-28]. Additionally, it is possible that changes in the metabolism of vitamin D notably the elevation of circulating vitamin $\mathrm{D}$ binding protein concentration may change the association of GC SNP with vitamin D status. This could be explained by the drastic change in the metabolism of vitamin $\mathrm{D}$ during pregnancy that causes variation in the factors associated with VDD during pregnancy compared to the non-pregnant state.

This study has several limitations as the data was collected in a public hospital where the findings could not be generalised to the pregnant women in private hospital. However, this study assessed a wide range of possible factors associated with maternal VDD: vitamin D intake from diet and supplements, estimates of sun exposure, skin type, clothing and SNPs. Owing to the limited resources, the sample size of this study was small which limited the number of SNPs that could be studied in the present study. However, two SNPs (rs4588 and rs7041) that were mostly reported to be associated with $25 \mathrm{OHD}$ in the previous studies were selected and investigated in this study. The sample size used in this study had a sufficient power to detect the prevalence and the associations of the demographic characteristics, lifestyle and GC SNPs (or diplotypes) with maternal VDD. To date, there is lack of consensus on the cut-off values used to define VDD. It is important to note that the results of factors associated with VDD in the present study might different if a different cut-off was used. However, the cut-off used in the present study was based on careful review by National Academy of Medicine (formerly known as Institute of Medicine) that suggests 25OHD level $<30 \mathrm{nmol} / \mathrm{L}$ is at increased risk of rickets, impaired fractional calcium absorption and decreased bone mineral content.

The high prevalence of maternal VDD reported in this study indicates the need for urgent development and implementation of strategies to improve maternal vitamin $\mathrm{D}$ status. In Malaysia, where sunlight is available throughout the year, advocating increasing sunlight exposure will be a cost-effective measure. Nonetheless, as a large majority of Malaysian women are veiled, advocating sun exposure may not increase the 25OHD level in majority of them. Veiled is a non-modifiable risk factor as almost all of the Malay women are veiled as part of religious requirement. Given that the food source of vitamin $\mathrm{D}$ is limited, it is a potential strategy to increase $25 \mathrm{OHD}$ level in pregnant women by vitamin D supplementation where a significant positive association of vitamin status with vitamin $\mathrm{D}$ intake from the supplement was found in this study. However, less than half (40.1\%) of the study participants consumed supplements containing vitamin D where prenatal multivitamin was the most prevalent supplement (66.7\%) consumed. Most of the pregnant women obtained their prenatal multivitamins (containing $10 \mu \mathrm{g}$ of vitamin D per capsule) from public health clinics during their antenatal visit while few of them bought the supplement themselves. It should be noted that in the Malaysian public health clinic, the provision of prenatal multivitamin is not universal. However, the provision is dependent on the availability and the requirement of a pregnant women. Universal provision of a prenatal multivitamin may be effective in improving the vitamin D status of pregnant women. Investigating the effectiveness of supplement consumption by pregnant women in randomised controlled trials could be the next step to develop national recommendations or policies for supplementation. Additionally, the significant association of GC SNPs (and GC diplotypes) with maternal VDD showed in the present and previous studies suggests that supplementation should be more personalised based on genotype and risk factors assessment, particularly in pregnant women.

\section{Conclusions}

Almost half of the pregnant women participated in this study were VDD $(25 \mathrm{OHD}<30 \mathrm{nmol} / \mathrm{L})$. Sun exposure was found not contribute to maternal vitamin $\mathrm{D}$ status. The contribution of GC rs4588 and rs7041 (or GC diplotypes) to maternal VDD was minimal but was significant. The findings showed that the risk of VDD was 4 times higher in veiled than unveiled women whereas vitamin D intake from foods and supplements were significantly associated with maternal VDD. Veiled clothing is a non-modifiable risk factors as majority of participants were veiled for religion requirement. Therefore, the current research suggests that food fortification and supplementation could be the potential strategy to improve vitamin D status among pregnant women.

\section{Supplementary Information}

The online version contains supplementary material available at https://doi. org/10.1186/s12884-020-03397-7.

Additional file 1. Questionnaire used in this study.

\section{Abbreviations}

25OHD: 25-hydroxyvitamin D; aOR: Adjusted odd ratio; BMl: Body Mass Index; BSA: Body surface area; Cl: Confidence interval; CYP27B1: Cytochrome P45027B1; CYP2R1: Cytochrome P450-2R1; DNA: Deoxyribonucleic acid; FFQ: Food Frequency Questionnaire; GC: Vitamin D binding protein; GWAS: Genomewide association studies; HWE: Hardy- Weinberg Equilibrium; IOM: Institute of Medicine; IQR: Interquartile range; LMP: Last menstrual period; PCR: Polymerase Chain Reaction; RFLP: Restriction fragment length polymorphism; SD: Standard deviation; SNPs: Single nucleotide 
polymorphisms; UHPLC: Ultra-High-Performance Liquid Chromatography; VDD: Vitamin D deficiency

\section{Acknowledgements}

We are grateful to all women who participated in this study. We acknowledge the midwives at Hospital Serdang, Selangor for their assistance in data collection.

\section{Authors' contributions}

SPL, RS and KHL contributed to conceptualization and methodology of the study. SPL and MT contributed to the funding acquisition. SSL, MT and KFR involved in data Curation. SSL administered the study, performed the statistical analyses and wrote the original manuscript. All the authors critically revised the manuscript and approved the final version.

\section{Funding}

This research was funded by Universiti Putra Malaysia via Research University Grant Scheme (RUGS) (S.P.L., grant number 04-03-11-1439RU) and Putra Young Initiative (IPM) (T.M., grant number GP-IPM/2013/9404100). The Universiti Putra Malaysia had no role in the design, analysis or writing of this article.

\section{Availability of data and materials}

The datasets used and/or analysed during the current study are available from the corresponding author on reasonable request. The questionnaire used in this study (supplementary file 1) are uploaded as supplementary material.

\section{Ethics approval and consent to participate}

Ethical approval was obtained from the Medical Research and Ethics Committee Ministry of Health Malaysia (MREC) with the ID: NMRR-15-78624865. Permission to commence the study in the labour suite of the Department of O\&G Hospital Serdang was sought from the Clinical Research Centre (CRC) Hospital Serdang. The written informed consent was obtained from pregnant women prior to data collection if they agreed to participate in the study.

\section{Consent for publication}

Not applicable.

\section{Competing interests}

The authors declare that they have no competing interests.

\section{Author details}

${ }^{1}$ Department of Nutrition, Faculty of Medicine and Health Sciences, Universiti Putra Malaysia, 43400 UPM Serdang, Selangor, Malaysia. ${ }^{2}$ Department of Biomedical Sciences, Faculty of Medicine and Health Sciences, Universiti Putra Malaysia, 43400 UPM Serdang, Selangor, Malaysia. ${ }^{3}$ Department of Genetics, Harvard Medical School, Boston, MA 02115, USA. ${ }^{4}$ Prince Court Medical Centre, 50450 Kuala Lumpur, Malaysia. ${ }^{5}$ Fetal Medicine and Gynaecology Centre (FMGC), 46200 Petaling Jaya, Selangor, Malaysia. ${ }^{6}$ Avisena Specialist Hospital, 40000 Shah Alam, Selangor, Malaysia. ${ }^{7}$ Research Centre of Excellence for Nutrition and Non-Communicable Diseases, Faculty of Medicine and Health Sciences, Universiti Putra Malaysia, 43300 UPM Serdang, Selangor, Malaysia.

Received: 8 May 2020 Accepted: 5 November 2020

Published online: 23 November 2020

\section{References}

1. Holick MF. Vitamin D deficiency. N Engl J Med. 2007;357(3):266-81.

2. Ankana G, Jennifer AT, Sarah F-S, Shiao YC, Melissa W, Janesh G, Mark DK, Stephane RG, Martin H. Vitamin D, the placenta and early pregnancy: effects on trophoblast function. J Endocrinol. 2018;236(2):R93-R103.

3. Karras SN, Wagner CL, Castracane VD. Understanding vitamin D metabolism in pregnancy: from physiology to pathophysiology and clinical outcomes. Metab Clin Exp. 2018;86:112-23.

4. Hypponen E, Cavadino A, Williams D, Fraser A, Vereczkey A, Fraser WD Banhidy F, Lawlor D, Czeizel AE. Vitamin D and pre-eclampsia: original data, systematic review and meta-analysis. Ann Nutr Metab. 2013;63(4):331-40.
5. Kiely ME, Zhang JY, Kinsella M, Khashan AS, Kenny LC. Vitamin D status is associated with uteroplacental dysfunction indicated by pre-eclampsia and small-for-gestational-age birth in a large prospective pregnancy cohort in Ireland with low vitamin D status. Am J Clin Nutr. 2016; 104(2):354-61.

6. Wilson RL, Leviton AJ, Leemaqz SY, Anderson PH, Grieger JA, Grzeskowiak LE, Verburg PE, McCowan L, Dekker GA, Bianco-Miotto T, et al. Vitamin D levels in an Australian and New Zealand cohort and the association with pregnancy outcome. BMC Pregnancy Childbirth. 2018;18(1):251.

7. Chen Y-H, Fu L, Hao J-H, Yu Z, Zhu P, Wang H, Xu Y-Y, Zhang C, Tao F-B, Xu $D-X$. Maternal vitamin $D$ deficiency during pregnancy elevates the risks of small for gestational age and low birth weight infants in Chinese population. J Clin Endocrinol Metab. 2015:100(5):1912-9.

8. Bodnar LM, Catov JM, Zmuda JM, Cooper ME, Parrott MS, Roberts JM, Marazita ML, Simhan HN. Maternal serum 25-hydroxyvitamin D concentrations are associated with small-for-gestational age births in white women. J Nutr. 2010;140(5):999-1006.

9. Qin LL, Lu FG, Yang SH, Xu HL, Luo BA. Does maternal vitamin D deficiency increase the risk of preterm birth: a meta-analysis of observational studies. Nutrients. 2016;8(5):301.

10. Saraf R, Morton SMB, Camargo CA, Grant CC. Global summary of maternal and newborn vitamin D status - a systematic review. Maternal Child Nutr. 2016;12(4):647-68.

11. Rodriguez A, Santa Marina L, Jimenez AM, Esplugues A, Ballester F, Espada M, Sunyer J, Morales E. Vitamin D status in pregnancy and determinants in a southern European cohort study. Paediatr Perinat Epidemiol. 2016;30(3):217-28.

12. Farrant HJ, Krishnaveni GV, Hill JC, Boucher BJ, Fisher DJ, Noonan K, Osmond C, Veena SR, Fall CH. Vitamin D insufficiency is common in Indian mothers but is not associated with gestational diabetes or variation in newborn size. Eur J Clin Nutr. 2009:63(5):646-52.

13. Ariyawatkul K, Lersbuasin P. Prevalence of vitamin D deficiency in cord blood of newborns and the association with maternal vitamin D status. Eur J Pediatr. 2018;177(10):1541-5.

14. Pratumvinit B, Wongkrajang $P$, Wataganara T, Hanyongyuth S, Nimmannit A, Chatsiricharoenkul S, Manonukul K, Reesukumal K. Maternal vitamin D status and its related factors in pregnant women in Bangkok, Thailand. PloS One. 2015;10(7):e0131126

15. Bukhary NBI, Isa ZM, Shamsuddin K, Lin KG, Mahdy ZA, Hassan H, Yeop NSH. Risk factors for antenatal hypovitaminosis D in an urban district in Malaysia. BMC Pregnancy Childbirth. 2016;16(1):156.

16. Public Health England: PHE publishes new advice on vitamin D. 2016

17. Health Council of the Netherlands. Evaluation of dietary reference values for vitamin D. The Hague: Health Council of the Netherlands; 2012.

18. Hossein-nezhad A, Holick MF. Vitamin D for health: a global perspective Mayo Clin Proc. 2013;88(7):720-55.

19. Ahn J, Yu K, Stolzenberg-Solomon R, Simon KC, McCullough ML, Gallicchio L, Jacobs EJ, Ascherio A, Helzlsouer K, Jacobs KB, et al. Genome-wide association study of circulating vitamin D levels. Hum Mol Genet. 2010; 19(13):2739-45.

20. Wang TJ, Zhang F, Richards JB, Kestenbaum B, van Meurs JB, Berry D, Kiel DP, Streeten EA, Ohlsson C, Koller DL, et al. Common genetic determinants of vitamin D insufficiency: a genome-wide association study. Lancet. 2010; 376(9736):180-8

21. Lucas RM, Ponsonby AL, Dear K, Valery PC, Taylor B, van der Mei I, McMichael AJ, Pender MP, Chapman C, Coulthard A, et al. Vitamin D status: multifactorial contribution of environment, genes and other factors in healthy Australian adults across a latitude gradient. J Steroid Biochem Mol Biol. 2013;136:300-8.

22. Suaini NHA, Koplin JJ, Ellis JA, Peters RL, Ponsonby A-L, Dharmage SC, Matheson MC, Wake M, Panjari M, Tan H-TT, et al. Environmental and genetic determinants of vitamin $D$ insufficiency in 12-month-old infants. J Steroid Biochem Mol Biol. 2014;144:445-54.

23. Jan Mohamed HJ, Rowan A, Fong B, Loy S-L. Maternal serum and breast milk vitamin D levels: findings from the Universiti Sains Malaysia pregnancy cohort study. PLoS One. 2014;9(7):e100705.

24. Lee $\mathrm{CL}$, Ng BK, Wu LL, Cheah FC, Othman H, Ismail NAM. Vitamin D deficiency in pregnancy at term: risk factors and pregnancy outcomes. Horm Mol Biol Clin Invest. 2017:31(3): 20170005.

25. Baca KM, Govil M, Zmuda JM, Simhan HN, Marazita ML, Bodnar LM. Vitamin D metabolic loci and vitamin D status in black and white pregnant women. Eur J Obstet Gynecol Reprod Biol. 2018;220:61-8. 
26. Ganz AB, Park H, Malysheva OV, Caudill MA. Vitamin D binding protein rs7041 genotype alters vitamin D metabolism in pregnant women. FASEB J. 2018;32(4):2012-20.

27. Tapia G, Mårild K, Stene LC, Haugen M, Størdal K, Cohen AS, Lie BA. Fetal and maternal genetic variants influencing neonatal vitamin D status. J Clin Endocrinol Metab. 2017;102(11):4072-9.

28. Anwar S, labal MP, Azam I, Habib A, Bhutta S, Soofi SB, Bhutta ZA. Urban and rural comparison of vitamin D status in Pakistani pregnant women and neonates. J Obstet Gynaecol. 2016;36(3):318-23.

29. Jolliffe DA, Walton RT, Griffiths CJ, Martineau AR. Single nucleotide polymorphisms in the vitamin D pathway associating with circulating concentrations of vitamin D metabolites and non-skeletal health outcomes: review of genetic association studies. J Steroid Biochem Mol Biol. 2016;164:18-29.

30. Gozdzik A, Zhu J, Wong BYL, Fu L, Cole DEC, Parra EJ. Association of vitamin $\mathrm{D}$ binding protein (VDBP) polymorphisms and serum $25(\mathrm{OH}) \mathrm{D}$ concentrations in a sample of young Canadian adults of different ancestry. J Steroid Biochem Mol Biol. 2011;127(3):405-12.

31. Arnaud J, Constans J. Affinity differences for vitamin D metabolites associated with the genetic isoforms of the human serum carrier protein (DBP). Hum Genet. 1993:92(2):183-8.

32. Boutin B, Galbraith RM, Arnaud P. Comparative affinity of the major genetic variants of human group-specific component (vitamin D-binding protein) for 25-(OH) vitamin D. J Steroid Biochem. 1989;32(1a):59-63.

33. Lauridsen AL, Vestergaard P, Hermann AP, Brot C, Heickendorff L, Mosekilde $L$, Nexo E. Plasma concentrations of 25-hydroxy-vitamin D and 1,25dihydroxy-vitamin D are related to the phenotype of Gc (vitamin D-binding protein): a cross-sectional study on 595 early postmenopausal women. Calcif Tissue Int. 2005;77(1):15-22.

34. Carpenter TO, Zhang JH, Parra E, Ellis BK, Simpson C, Lee WM, Balko J, Fu L, Wong BYL, Cole DEC. Vitamin D binding protein is a key determinant of 25hydroxyvitamin D levels in infants and toddlers. J Bone Miner Res. 2013; 28(1):213-21.

35. Bikle D, Gee E, Halloran B, Haddad JG. Free 1,25-dihydroxyvitamin D levels in serum from normal subjects, pregnant subjects, and subjects with liver disease. J Clin Invest. 1984;74(6):1966-71.

36. Daniel WW. Biostatistics: A Foundation for Analysis in The Health Sciences 7th edition. New York: John Wiley \& Sons; 1999.

37. Hall LM, Kimlin MG, Aronov PA, Hammock BD, Slusser JR, Woodhouse LR, Stephensen CB. Vitamin D intake needed to maintain target serum 25hydroxyvitamin D concentrations in participants with low sun exposure and dark skin pigmentation is substantially higher than current recommendations. J Nutr. 2010;140(3):542-50.

38. Jamil NA, Yew MH, Noor Hafizah Y, Gray SR, Poh BK, Macdonald HM Estimated vitamin D synthesis and dietary vitamin D intake among Asians in two distinct geographical locations (Kuala Lumpur, $3^{\circ} \mathrm{N}$ v. Aberdeen, $57^{\circ} \mathrm{N}$ ) and climates. Public Health Nutr. 2018; 21(17):3118-24.

39. Fitzpatrick TB. The validity and practicality of sun-reactive skin types I through VI. Arch Dermatol. 1988;124(6):869-71.

40. Cabaset S, Krieger J-P, Richard A, Elgizouli M, Nieters A, Rohrmann S, Quack Lötscher KC. Vitamin D status and its determinants in healthy pregnant women living in Switzerland in the first trimester of pregnancy. BMC Pregnancy Childbirth. 2019;19(1):10.

41. Zaleha MI, Khadijah S, Bukhary N, Khor GL, Zaleha AM, Haslinda H, Hana NS, Hasanain Faisal G. Development and validation of a food frequency Questionaire for vitamin D intake among urban pregnant women in Malaysia. Malaysia J Nutr. 2015;21(2):179-90.

42. Institute of Medicine. Dietary Reference Intakes for Calcium and Vitamin D. Washington: The National Academies Press; 2011.

43. John W. Graham. Missing Data Analysis: Making It Work in the Real World. Annual Review of Psychology 2009;60(1):549-76.

44. Lee S-S, Loh SP, Subramaniam R, Tusimin M, Ling K-H, Farah K. Association of maternal and cord plasma total, free and bioavailable 25Hyrodroxyvitamin D with neonatal anthropometric measurements at birth: a preliminary study in a private hospital. Malaysian J Med Health Sci. 2020; 16(1):24-31.

45. Kiely M, O'Donovan SM, Kenny LC, Hourihane JO, Irvine AD, Murray DM. Vitamin D metabolite concentrations in umbilical cord blood serum and associations with clinical characteristics in a large prospective mother-infant cohort in Ireland. J Steroid Biochem Mol Biol. 2017:167:162-8.
46. Wuertz C, Gilbert P, Baier W, Kunz C. Cross-sectional study of factors that influence the 25-hydroxyvitamin D status in pregnant women and in cord blood in Germany. Br J Nutr. 2013;110(10):1895-902.

47. Yun C, Chen J, He Y, Mao D, Wang R, Zhang Y, Yang C, Piao J, Yang X Vitamin $D$ deficiency prevalence and risk factors among pregnant Chinese women. Public Health Nutr. 2015;20(10):1746-54.

48. Kanatani KT, Nakayama T, Adachi Y, Hamazaki K, Onishi K, Konishi Y, Kawanishi Y, Go T, Sato K, Kurozawa Y, et al. High frequency of vitamin D deficiency in current pregnant Japanese women associated with UV avoidance and hypo-vitamin D diet. PLoS One. 2019;14(3):e0213264.

49. Karras S, Paschou SA, Kandaraki E, Anagnostis P, Annweiler C, Tarlatzis BC, Hollis BW, Grant WB, Goulis DG. Hypovitaminosis D in pregnancy in the Mediterranean region: a systematic review. Eur J Clin Nutr. 2016; 70(9):979-86.

50. Al-Musharaf S, Fouda MA, Turkestani IZ, Al-Ajlan A, Sabico S, Alnaami AM, Wani K, Hussain SD, Alraqebah B, Al-Serehi A, et al. Vitamin D deficiency prevalence and predictors in early pregnancy among Arab women. Nutrients. 2018;10(4):489.

51. Brembeck $\mathrm{P}$, Winkvist A, Olausson $\mathrm{H}$. Determinants of vitamin $\mathrm{D}$ status in pregnant fair-skinned women in Sweden. Br J Nutr. 2013;110(5):856-64.

52. Bärebring L, Schoenmakers I, Glantz A, Hulthén L, Jagner $\AA$, Ellis J, Bärebring M, Bullarbo M, Augustin H. Vitamin D status during pregnancy in a multiethnic population-representative Swedish cohort. Nutrients. 2016;8(10):655

53. Wierzejska R, Jarosz M, Klemińska-Nowak M, Tomaszewska M, Sawicki W, Bachanek M, Siuba-Strzelińska M. Maternal and cord blood vitamin D status and anthropometric measurements in term newborns at birth. Front Endocrinol. 2018;9:9.

54. Vinkhuyzen AAE, Eyles DW, Burne TH, Blanken LME, Kruithof CJ, Verhulst F, Jaddoe WW, Tiemeier H, McGrath JJ. Prevalence and predictors of vitamin D deficiency based on maternal mid-gestation and neonatal cord bloods: the generation R study. J Steroid Biochem Mol Biol. 2016;164:161-7.

55. Krieger J-P, Cabaset S, Canonica C, Christoffel L, Richard A, Schröder T, von Wattenwyl BL, Rohrmann S, Lötscher KQ. Prevalence and determinants of vitamin $\mathrm{D}$ deficiency in the third trimester of pregnancy: a multicentre study in Switzerland. Br J Nutr. 2018;119(3):299-309.

56. Dovnik A, Mujezinovic F, Treiber M, Pecovnik Balon B, Gorenjak M, Maver U, Takac I. Determinants of maternal vitamin D concentrations in Slovenia : a prospective observational study. Wien Klin Wochenschr. 2017;129(1-2):21-8.

57. Barebring L, Bullarbo M, Glantz A, Hulthen L, Ellis J, Jagner A, Schoenmakers I, Winkvist A, Augustin $\mathrm{H}$. Trajectory of vitamin D status during pregnancy in relation to neonatal birth size and fetal survival: a prospective cohort study. BMC Pregnancy Childbirth. 2018;18(1):51.

58. Shao B, Jiang S, Muyiduli X, Wang S, Mo M, Li M, Wang Z, Yu Y. Vitamin D pathway gene polymorphisms influenced vitamin $D$ level among pregnant women. Clin Nutr. 2018;37(6, Part A):2230-7.

\section{Publisher's Note}

Springer Nature remains neutral with regard to jurisdictional claims in published maps and institutional affiliations.

Ready to submit your research? Choose BMC and benefit from:

- fast, convenient online submission

- thorough peer review by experienced researchers in your field

- rapid publication on acceptance

- support for research data, including large and complex data types

- gold Open Access which fosters wider collaboration and increased citations

- maximum visibility for your research: over $100 \mathrm{M}$ website views per year

At $\mathrm{BMC}$, research is always in progress.

Learn more biomedcentral.com/submissions 